\title{
MiR-592 Promotes Gastric Cancer Proliferation, Migration, and Invasion Through the PI3K/AKT and MAPK/ERK Signaling Pathways by Targeting Spry2
}

\author{
Yu He ${ }^{b}$ Yugang Ge ${ }^{b}$ Mingkun Jiang ${ }^{b}$ Jundong Zhouc Dakui Luo ${ }^{b}$ Hao Fan \\ Liang Shib Linling Lin ${ }^{b}$ Li Yanga,b \\ aDepartment of General Surgery, Liyang People's Hospital, Liyang Branch Hospital of Jiangsu Province \\ Hospital, Liyang, Jiangsu, bDepartment of General Surgery, the First Affiliated Hospital of Nanjing \\ Medical University, Nanjing, Jiangsu, 'Suzhou Cancer Center Core Laboratory, Nanjing Medical \\ University Affiliated Suzhou Hospital, Suzhou, Jiangsu, China
}

\section{Key Words}

Mir-592 • Spry2 • EMT • PI3K/AKT and MAPK/ERK signaling pathways • Gastric cancer

\begin{abstract}
Background/Aims: Gastric cancer (GC) is one of the most prevalent digestive malignancies. MicroRNAs (miRNAs) are involved in multiple cellular processes, including oncogenesis, and miR-592 itself participates in many malignancies; however, its role in GC remains unknown. In this study, we investigated the expression and molecular mechanisms of miR-592 in GC. Methods: Quantitative real-time PCR and immunohistochemistry were performed to determine the expression of miR-592 and its putative targets in human tissues and cell lines. Proliferation, migration, and invasion were evaluated by Cell Counting Kit-8, population doubling time, colony formation, Transwell, and wound-healing assays in transfected GC cells in vitro. A dual-luciferase reporter assay was used to determine whether miR-592 could directly bind its target. A tumorigenesis assay was used to study whether miR-592 affected GC growth in vivo. Proteins involved in signaling pathways and the epithelial-mesenchymal transition (EMT) were detected with western blot. Results: The ectopic expression of miR-592 promoted GC proliferation, migration, and invasion in vitro and facilitated tumorigenesis in vivo. Spry2 was a direct target of miR-592 and Spry2 overexpression partially counteracted the effects of miR-592. miR-592 induced the EMT and promoted its progression in GC via the PI3K/AKT and MAPK/ERK signaling pathways by inhibiting Spry2. Conclusions: Overexpression of miR-592 promotes GC proliferation, migration, and invasion and induces the EMT via the PI3K/AKT and MAPK/ERK signaling pathways by inhibiting Spry2, suggesting a potential therapeutic target for GC.

Y. He, Y. Ge, M. Jiang and J. Zhou contributed equally to this work.

\begin{tabular}{ll}
\hline Dr. Li Yang & Dept. of General Surgery, Liyang People's Hospital, Liyang Branch Hospital of Jiangsu \\
& Province Hospital Liyang, Jiangsu 213300 (China) \\
& Tel.+86 025-83718836, Fax +86 025-83718836, E-Mail pwkyangli@163.com
\end{tabular}




\section{Cellular Physiology Cell Physiol Biochem 2018;47:1465-1481

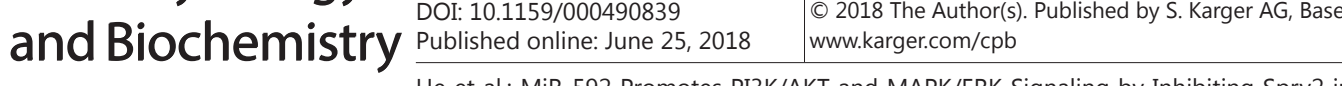 GC}

\section{Introduction}

Gastric cancer (GC) is one of the most prevalent digestive malignancies, the fourth most frequent malignancy, and the third leading cause of cancer-associated death worldwide [1]. In China, with 679, 100 new cases and 498, 000 deaths in 2015, both its morbidity and mortality rank second only to lung cancer [2]. Despite advances in early diagnosis and surgical techniques, patients with advanced GC still have a poor prognosis with a 5-year overall survival below 25\% [3]. Because multiple factors, including heredity and genetics, contribute to the intricate process of gastric carcinogenesis [4], identification of promising strategies aimed at revealing the molecular mechanisms underlying GC is an urgent issue.

MicroRNAs are endogenous, highly conserved, small noncoding RNAs of approximately 19-24 nucleotides in length [5]. They negatively exert a vital role in regulating gene expression, mainly by binding to the 3' untranslated region (3'UTR) of target mRNA at the post-transcriptional level, causing its degradation or translational suppression [6, 7]. miRNAs participate in various biological activities in cells, such as proliferation, migration, invasion, and apoptosis [8]. Many lines of evidence suggest that aberrant expression of miRNA also plays a role in cancer progression by affecting exclusive oncogenes or tumor suppressors [9-11].

According to The Cancer Genome Atlas (TCGA) database, miR-592 is abnormally overexpressed in GC tissues compared with adjacent normal tissues. miR-592 is also dysregulated in diverse human cancers [12-16], acting as an oncogene in cancers such as colorectal $[12,13]$ and prostate [14]. In contrast, miR-592 serves as a tumor suppressor in hepatocellular carcinoma $[15,16]$. Nevertheless, the potential roles and molecular mechanisms of miR-592 in GC need further investigation.

Sprouty, which was first discovered in Drosophila, is a potent antagonist of the FGFRinduced Ras/MAPK signal pathway [17, 18]. As one of four mammalian isoforms, Sprouty2 manifests the highest evolutionary conservation and its loss or dysregulation has been linked to ovarian carcinoma [19], renal carcinoma [20], and lung cancer [21]. However, Spry2 also serves as an oncogene driving the epithelial-mesenchymal transition (EMT) in colorectal cancer [22]. In addition, Spry2 plays a suppressive role in GC [23].

In this study, we investigated the role of miR-592 in GC and hypothesized that Spry2 might be one of the putative direct targets of miR-592 through bioinformatics predictions and experimental validation. Our results indicated that miR-592 overexpression could promote the progression and development of GC by targeting Spry2 through the PI3K/AKT and MAPK/ERK signaling pathways in vitro and in vivo. More importantly, these findings may indicate a therapeutic target for GC.

\section{Materials and Methods}

\section{Human tissue samples}

Human GC tissues and paired adjacent normal tissues were acquired from $70 \mathrm{GC}$ patients who underwent radical gastrectomy at the Department of General Surgery, The First Affiliated Hospital of Nanjing Medical University, China. After resection, all specimens were immediately stored in liquid nitrogen and the relevant histopathology was confirmed by pathologists. This study was approved by the First Affiliated Hospital of Nanjing Medical University Ethics Committees and all patients or relatives signed informed consent.

\section{Cell lines}

Human GC cell lines (SGC7901, BGC823, MGC803, and AGS) and human normal gastric mucous epithelium cells (GES-1) were purchased from the American Type Culture Collection (Manassas, VA, USA). They were cultured in RPMI-1640 medium supplemented with 10\% fetal bovine serum (FBS; Wisent Inc., St. Bruno, Canada) and $1 \%$ antibiotics (100 U/ml penicillin $\mathrm{G}$ and $100 \mu \mathrm{g} / \mathrm{ml}$ streptomycin). The cells were incubated in a humidified atmosphere containing $5 \% \mathrm{CO}_{2}$ at $37^{\circ} \mathrm{C}$. 


\section{Cellular Physiology Cell Physiol Biochem 2018;47:1465-1481 \\ \begin{tabular}{ll|l} 
DOI: 10.1159/000490839 & $\begin{array}{l}\text { () } 2018 \text { The Author(s). Published by S. Karger AG, Base } \\
\text { www.karger.com/cpb }\end{array}$ \\
\cline { 2 - 3 }
\end{tabular} \\ He et al.: MiR-592 Promotes PI3K/AKT and MAPK/ERK Signaling by Inhibiting Spry2 in}

GC

RNA extraction and quantitative real-time PCR

Total RNA, including miRNA and mRNA, was extracted from cells and tissues with Trizol reagent (Invitrogen, Carlsbad, CA, USA) according to the manufacturer's instructions. Subsequently, we applied PrimeScript RT Reagent (Takara, Japan) to synthesize cDNA for human Spry2. To detect miRNA expression, a poly(A) polymerase was used to polyadenylate and elongate the miRNA, and then an Oligo-dT adaptor with a universal tag sequence on its 5' end was mixed with the decorated RNA. The sequence of the Oligo-dT adaptor was as follows: 5'-GCGAGCACAG AATTAATACG ACTCACTATA GG(T)18-3'. Finally, the cDNA of miR592 was acquired by using a ReverAid Transcriptase Kit (Thermo Scientific, Waltham, MA, USA). Quantitative real-time PCR (qRT-PCR) was performed on a 7500 Real-time PCR System (Applied Biosystems, Carlsbad, CA, USA) with a SYBR Premix Ex Taq Kit (Vazyme, Nanjing, China) to determine the relative expression of miR-592 and SPRY2. U6 snRNA and $\beta$-actin were used as the internal controls for miR-592 and Spry2, respectively. The specific primers were as follows: has-miR-592, forward: 5'-TTGTGTCAAT ATGCGATGAT GT3'; Universal: 5'-GCGAGCACAG AATTAATACG AC-3'; U6, forward: 5'-CTCGCTTCGG CAGCACA-3'; U6, reverse: 5'-AACGCTTCAC GAATTTGCGT-3'; has-Spry2, forward: 5'-CTCGGCCCAG AACGTGATT-3', hsa-Spry2, reverse: 5'-GGCAAAAAGA GGGACATGAC AC-3'; $\beta$-actin, forward: 5'-GCATCGTCAC CAACTGGGAC-3', $\beta$-actin, reverse: 5'-ACCTGGCCGT CAGGCAGCTC-3'. All procedures were performed in triplicate and the relative expression was calculated by means of the $2^{-\Delta \Delta \mathrm{CT}}$ method.

\section{Western blot assay}

Total protein was extracted using RIPA lysis buffer (Beyotime, Shanghai, China) supplemented with protease inhibitor, phosphatase inhibitor, and phenylmethanesulfonyl fluoride. After scraping, oscillation, and centrifugation at $14,000 \mathrm{rpm}$ for $15 \mathrm{~min}$ at $4^{\circ} \mathrm{C}$, the supernatant was collected and mixed with sodium dodecyl sulfate loading buffer. The solution was boiled for $5 \mathrm{~min}$ and stored at $-20^{\circ} \mathrm{C}$. Isolated proteins from cells and tissues were then electrophoresed on $10 \%$ sodium dodecyl sulfate polyacrylamide gel electrophoresis and transferred to a polyvinylidene fluoride membrane (Bio-Rad, CA, USA). Afterward, the membrane was blocked by $5 \%$ non-fat milk at room temperature for $2 \mathrm{~h}$ and incubated with specific primary antibodies $(1: 1,000)$ at $4^{\circ} \mathrm{C}$ overnight. The next day, after recycling antibodies, the membrane was washed three times with Tris-buffered saline with Tween-20 (TBST) for 15 min each and then incubated with secondary antibodies $(1: 10,000)$ at room temperature for $2 \mathrm{~h}$. After three more washes with TBST, the relative expression levels of the protein were detected via an enhanced chemiluminescence detection system. The primary antibodies were as follows: Spry2 (1:1, 000, Abcam, Cambridge, UK); E-cadherin, vimentin, N-cadherin, ERK, p-ERK, AKT, and p-AKT (1:1, 000, Cell Signaling Technology, Danvers, MA, USA); GAPDH as internal control; $(1: 1,000$, Cell Signaling Technology). The experiments were performed in triplicate and the relative protein expressions were quantified and compared via grayscale analysis using ImageJ.

\section{Lentivirus construction and cell transfection}

To overexpress or knockdown miR-592 in GC cells, commercially available LV2-has-miR-592-mimics vector (miR-592-mimics) and LV2-has-miR-592 inhibitor vector (miR-592-inhibitor) were constructed (GenePharma, Shanghai, China). The LV2 empty vector construct (miR-NC) functioned as a negative control. In brief, pri-miR-592 sequences were synthesized and cloned into the PgLV2-U6-Puro Vector (LV2); all vectors were verified by DNA sequencing. $293 \mathrm{~T}$ cells were cotransfected with the lentiviral expression construct and packing plasmids and then viral particles were collected and the titer determined before the infection of target cells. When the GC cell lines SGC7901 and BGC823 reached 40-50\% confluence, they were infected with the lentiviral vectors at the appropriate multiplicity of infection: 20 for SGC7901 cells and 50 for BGC823 cells. Stably transfected cell lines were acquired by using $5 \mu \mathrm{g} / \mathrm{ml}$ puromycin (Sigma, USA) for 1 week. Lentiviral vector containing Spry2 coding sequence (LV-Spry2) and the corresponding negative control (vector) were also made by GenePharma Biotech (Shanghai, China). The synthesized coding sequence of Spry 2 was cloned into the vector and used to generate the stable cell lines by the above methods.

\section{Dual-luciferase reporter assay}

To determine whether Spry2 is a direct target of miR-592, the 3'UTR sequence of Spry2 mRNA with its full length of 782 nucleotides including wild-type or mutated miR-592 binding sites was synthesized by GeneScript (Nanjing, China). The wild-type 3'UTR including putative binding sites (5' AUACUACAUG 


\section{Cellular Physiology Cell Physiol Biochem 2018;47:1465-1481

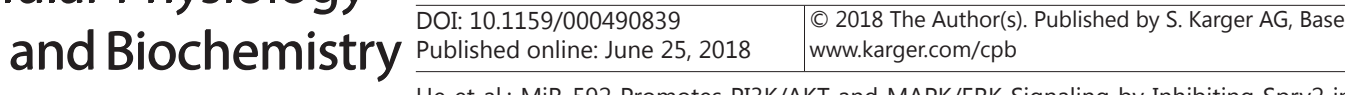

GCACAGACAC AAA 3' [position: 404-426]) and corresponding mutated sites (5' AUACUACAUG GCACAGCAGU CAA 3') was cloned into the FseI and XbaI restriction sites of the pGL3 luciferase control reporter vector (Promega, Madison, WI, USA) to obtain the Spry2 3'UTR reporter constructs (pGL3-WT-Spry2 and pGL3MUT-Spry2). SGC7901 and BGC823 cells were seeded in 24-well plates at $5 \times 10^{4}$ cells per well and incubated for $24 \mathrm{~h}$. The cells were cotransfected were $120 \mathrm{ng}$ pGL3-WT-Spry2 or PGL3-MUT-Spry2 accompanied by $40 \mathrm{nM}$ miR-592 mimics or negative control using Lipofectamine 2000 (Invitrogen). Then, $48 \mathrm{~h}$ after transfection, Firefly and Renilla luciferase activities were measured using the dual-luciferase reporter assay system (E1910, Promega) according to the manufacturer's protocol. Renilla luciferase expression plasmid (10 ng) was also transfected into the cells to act as the internal reference. This assay was performed in triplicate and the results are expressed in the form of a ratio of firefly fluorescence to Renilla fluorescence.

\section{Immunohistochemistry}

All tissue samples were fixed in $4 \%$ formalin, dehydrated by graded ethanol, and then embedded in paraffin. Sections ( $4 \mu \mathrm{m}$ thick) were cut on a histotome, dewaxed in dimethylbenzene, and rehydrated, then steeped in sodium citrate and 3\% hydrogen peroxide for antigen retrieval and to quench endogenous peroxidase activity. Sections were incubated overnight at $4^{\circ} \mathrm{C}$ with primary antibody. After being washed with phosphate buffered saline (PBS), the slices were incubated with horseradish peroxidase polymerconjugated secondary antibody at $37^{\circ} \mathrm{C}$ for $1 \mathrm{~h}$, and then stained with 3,3 -diaminobenzidine solution for 3 min to visualize the staining. Hematoxylin was used to counterstain nuclei.

\section{Cell proliferation assay}

To examine the proliferation of GC cells, $1 \times 10^{3}$ cells/well were seeded in 96-well plates and cultured in RPMI-1640 medium supplemented with 10\% FBS for 6 days. At a set time point every day, the medium was exchanged with a solution containing $10 \mu \mathrm{l}$ Cell Counting Kit-8 (CCK8; Beyotime) according to the manufacturer's instructions with $100 \mu \mathrm{l}$ RPMI-1640 and incubated at $37^{\circ} \mathrm{C}$ for $2 \mathrm{~h}$. Absorbance was then measured at $450 \mathrm{~nm}$, which obtains the appropriate OD value for evaluating cell numbers.

\section{Population doubling time determination}

When cell density reached approximately 70-90\%, the cells were trypsinized and seeded in 96-well plates with $1 \times 10^{3}$ cells per well in five replicates. Cells were incubated in $100 \mu$ medium for 6 days and the absorbance was measured at a set point every day. Cell proliferation was determined via characterization of the logarithmic phase of growth with the population doubling time (PDT): PDT $=\left(\log 2 \times\left(t_{2}-t_{1}\right)\right) /\left(\log N_{2}-\right.$ $\log \mathrm{N}_{1}$ ), where $\mathrm{N}_{2}$ is the number of cells harvested at the end of the growth period, $\mathrm{N}_{1}$ indicates the initial cell number, and $\left(t_{2}-t_{1}\right)$ means the counting time interval. The average PDT was calculated for the five replicates and the experiments were performed in triplicate.

\section{Colony formation assay}

Stably transfected GC cells were seeded in 6-well plates (500 cells/well) and cultured in an incubator with $5 \% \mathrm{CO}_{2}$ at $37^{\circ} \mathrm{C}$ for about 2 weeks. When clear colonies formed, the cells were washed with PBS and fixed by $70 \%$ ethanol for $3 \mathrm{~min}$. Then, the plates were stained with 1\% crystal violet (Beyotime) for $30 \mathrm{~min}$. When a colony containing 50 cells or more was found under the microscope, the number of colonies was counted.

\section{Transwell assay}

Transwells with an 8- $\mu \mathrm{m}$ pore size (Corning Costar Corp., Corning, NY, USA) were used to test the migratory and invasive abilities of treated cells. Briefly, $2 \times 10^{4}$ cells were placed in the top chamber in $200 \mu \mathrm{l}$ serum-free medium, and $500 \mu \mathrm{l}$ complete culture medium (with $10 \% \mathrm{FBS}$ ) was added to the lower chamber to act as a chemoattractant. Twenty-four hours after incubation, the cells were fixed and then stained with $1 \%$ crystal violet for $20 \mathrm{~min}$. The cells on the upper layer of the chambers that could not migrate to the opposite surface were carefully removed with a cotton swab, whereas the cells on the lower surface were imaged and counted under an inverted microscope (Olympus Corp., Tokyo, Japan) at 200× magnification with five random fields for each membrane. This approach was mainly used to determine migratory ability. To investigate the invasive ability of cells, $0.1 \mathrm{ml}$ Matrigel ( $50 \mu \mathrm{g} / \mathrm{ml}$, BD Biosciences, San Jose, CA, USA) was added onto the plate surface and the cells were incubated for $2 \mathrm{~h}$ and then assessed as indicated above. 


\section{Cellular Physiology Cell Physiol Biochem 2018;47:1465-1481 \\ \begin{tabular}{ll|l}
\hline DOI: 10.1159/000490839 & $\begin{array}{l}\text { () } 2018 \text { The Author(s). Published by S. Karger AG, Base } \\
\text { www.karger.com/cpb }\end{array}$ \\
\hline
\end{tabular} GC}

Wound-healing assay

SGC7901 and BGC823 cells $\left(5 \times 10^{5}\right)$ were incubated in 6-well plates until they reached confluency. Linear scratch wounds were created in the center of each well with a 200- $\mu$ sterile pipette tip. Cells in suspension were washed several times in PBS and adherent cells were cultured in serum-free medium. After $0 \mathrm{~h}, 24 \mathrm{~h}$, and $48 \mathrm{~h}$, images were taken to observe the wounds at the same fields under the microscope and the separation distance between wound sides was calculated. The experiments were performed in triplicate.

\section{In vivo tumorigenicity}

Forty 4-week-old BALB/c nude mice were purchased from the Animal Centre of Nanjing Medical University. All animal experiments were approved and consistent with the Institutional Animal Care and Use Committee of Nanjing Medical University. The mice were randomly divided into six groups. Stably transfected GC cells (SGC7901-miR-592-mimics, SGC7901-miR-592-inhibitor, and SGC7901-NC; BGC823miR-592-mimics, BGC823-miR-592-inhibitor, and BGC823-NC) were suspended in PBS and inoculated subcutaneously into two flanks of the mice at a density of $1 \times 10^{6}$ cells $/ 100 \mu \mathrm{PBS}$. The tumor volumes were measured with Vernier calipers every 4 days for 3 weeks until the mice were euthanized and the relative tumor volume doubling time was determined using the PDT formula introduced above. The implanted tumor volumes were calculated as volume $=\left(\mathrm{L} \times \mathrm{W}^{2}\right) / 2$, where $\mathrm{L}$ is the tumor length and $\mathrm{W}$ is the tumor width.

\section{Statistical analysis}

Data from three independent experiments are shown as the mean \pm standard deviation. Using SPSS software version 19.0, differences between two groups were determined by a two-tailed Student's $t$ test. Clinicopathological features were compared by Pearson $\chi^{2}$ tests. Analysis of variance was used to compare treated and control groups. $P<0.05$ was considered statistically significant.

\section{Results}

\section{miR-592 is upregulated in GC tissues and cells}

According to the TCGA database, which includes 413 primary GC tissues and 43 adjacent normal tissues, miR-592 expression was significantly higher in GC tissues (Fig. 1A). To verify whether miR-592 was dysregulated in GC tissues, 70 pairs of GC tissues and adjacent normal tissues were collected to determine the relative expression of miR-592 using qRTPCR. As shown in Fig. 1B and C, the expression of miR-592 was upregulated in GC tissues. Specifically, when data were normalized to Log2, the miR-592 expression of GC tissues was increased in 51 of the paired cases and decreased in the remaining 19 pairs compared with the corresponding adjacent tissues. In addition, the expression of miR-592 in normal GES-1 and GC cell lines (SGC7901, MGC803, BGC823, and AGS) was further examined with qRTPCR. As shown in Fig. 1D, the expression of miR-592 was markedly higher in GC cells. Our results were consistent with the data in TCGA and indicated that the expression of miR-592 was upregulated in both GC tissues and cells.

Next, we analyzed the correlation between miR-592 expression and clinicopathologic features. GC patients $(n=70)$ were divided into two groups based on the relative expression of miR-592 (whether higher or not than the mean expression): the high miR-592 expression group $(n=33)$ and the low miR-592 expression group $(n=37)$. As shown in Table 1, high miR-592 expression was associated with tumor size, histological type, and lymph node metastasis. The analytical data indicated that miR-592 had considerable influence on the development and progression of GC.

\section{miR-592 facilitates the proliferation of GC}

We postulated that miR-592 would play an important role in GC due to its high expression in both GC tissues and cells. To confirm this hypothesis, we selected SGC7901 and BGC823 cells for biological function experiments in line with the miR-592 expression results 


\section{Cellular Physiology \\ Cell Physiol Biochem 2018;47:1465-1481

Fig. 1. The expression of miR-592 in GC tissues and GC cells. (A) The relative expression of miR-592 in 413 primary GC tissues and 43 adjacent normal tissues in TCGA database. (B) The expression levels of miR-592 in 70 pairs of human GC tissues and adjacent tissues. (C) The miR-592 expressions are represented as $\log 2$ fold change (tumor/normal), defined as ' $>0$ ' for overexpression and ' $<0$ ' for underexpression. (D) The expression levels of miR-592 in GC cells and GES-1 were detected by qRT-PCR. (E) The efficacy of transfection was verified in two cell lines transfected with miR-592-mimics and miR-592-inhibitor lentivirus. ${ }^{*} \mathrm{P}<0.05$, ${ }^{* *} \mathrm{P}<0.01$, *** $\mathrm{P}<0.001$. The data expressed as the mean \pm SD.

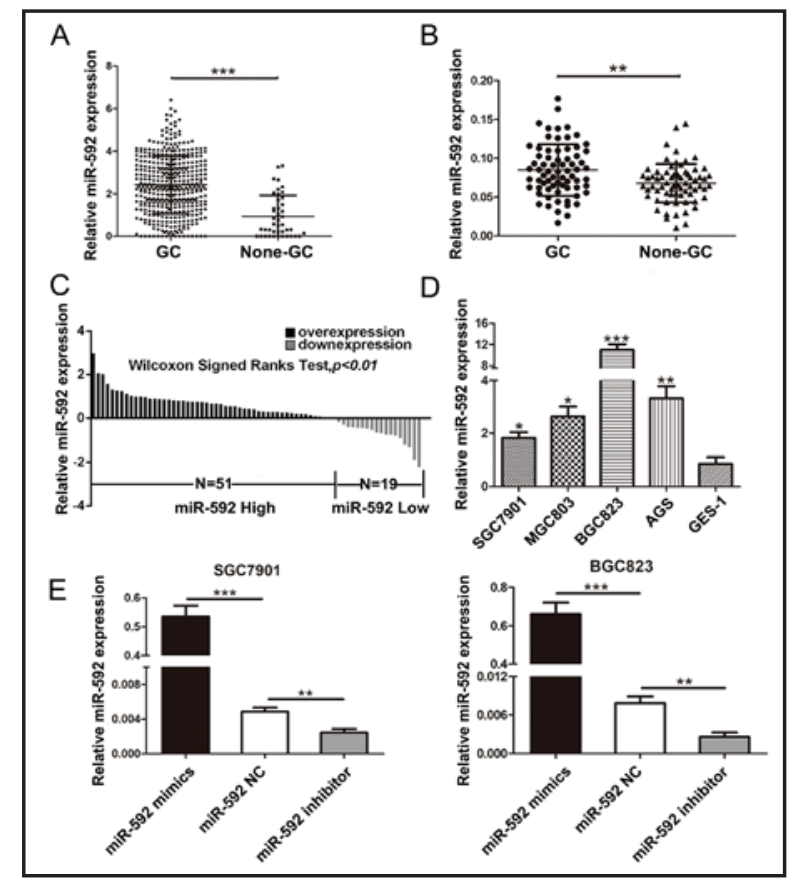

in various GC cells determined with qRT-PCR (relatively low in SGC7901 and relatively high in BGC823). In addition, the two cell lines were stably transfected with miR-592-mimics or -inhibitor lentivirus and the efficacy was determined using qRT-PCR. As shown in Fig. 1E, the relative expression of miR-592 was markedly increased and decreased in SGC7901 cells transfected with miR-592-mimics and -inhibitor, respectively, versus the negative control groups. The same results were achieved in the BGC823 cell line.

A CCK8 assay was conducted to probe the effect of miR-592 on GC cell proliferation. Ectopic expression of miR-592 boosted the proliferation rate of both SGC7901 and BGC823 cell lines compared with control groups and the opposite effects were detected in the cells subjected to miR-592 expression knockdown (Fig. 2A). The PDT was calculated and compared to further verify the effect of miR-592 on GC proliferation (Fig. 2B). Compared with the control group, the miR-592-mimics group showed a shortened PDT and the miR592-inhibitor group had a longer PDT. Additionally, a colony formation assay was carried out to reflect the population dependence and proliferation capacity of GC cells. The results were consistent with the CCK8 assay and showed that upregulated expression of miR-592 promoted the colony formation ability of the two chosen cell lines versus the control group and that downregulated expression reversed the effect (Fig. 2C). These two in vitro studies indicated that the expression of miR-592 was positively correlated with the proliferation of GC, which means that overexpressed miR-592 could facilitate the proliferation of GC, with miR-592 knockdown having the opposite effects.

\section{miR-592 promotes GC migration and invasion}

To further validate the oncogenic role of miR-592 in GC cells, wound-healing and Transwell assays were performed. In the wound-healing assay, overexpression of miR-592 increased the migration rate of both types of cells at two set time points. In contrast, reduced expression of miR-592 decreased the number of migratory cells (Fig. 2D). In the Transwell assay, when miR-592 was upregulated, the number of migrated cells was dramatically increased, and the opposite results were observed when miR-592 was downregulated at the two time points (Fig. 2E). The number of invasive SGC7901 and BGC823 cells was also increased when the chamber was coated with Matrigel, compared with the negative control, and knockdown of miR-592 showed the opposite effect (Fig. 2F). Taken together, these results demonstrated that miR-592 promotes the migration and invasion of GC cells in vitro. 


\section{Cellular Physiology \\ Cell Physiol Biochem 2018;47:1465-1481 and Biochemistry

Fig. 2. miR-592 promoted cell proliferation, migration and invasion and promoted tumorigenicity in vivo. (A) CCK8 assay was used to assess the cell proliferation between miR592-mimics, miR-592-inhibitor and corresponding negative group in SGC7901 and BGC823 cell lines. (B) Relevant population doubling time (PDT) was calculated and compared in the treated groups (C) Effects of miR-592 alteration on colony formation in two cell lines. (D) Wound healing was performed to determine the ability of cell migration after transfected with miR-592-mimics and miR-592-inhibitor, the migratory rate was calculated by migration distance / original width, scale bar: $400 \mu \mathrm{m}$. (E) and (F) Transwell migration and Matrigel invasion assays were conducted in each group, the migratory and invasive cell numbers were counted under the magnification of $\times 200$, scale bar: $200 \mu \mathrm{m}$. (G) Xenograft tumors were harvested from different groups of nude mice transfected with miR-NC, miR592-mimics and miR-592-inhibitor. (H-J) Growth curve of tumor volumes, doubling time and weight were calculated, Date are shown as mean $\pm \mathrm{SD}$. (K, L) The expression of miR-592 miRNA level and spry2 protein level were determined by qRTPCR and western blot respectively. * $\mathrm{P}<0.05, * * \mathrm{P}<0.01, * * *$ $\mathrm{P}<0.001$. The data expressed as the mean \pm SD.
$\mathrm{GC}$

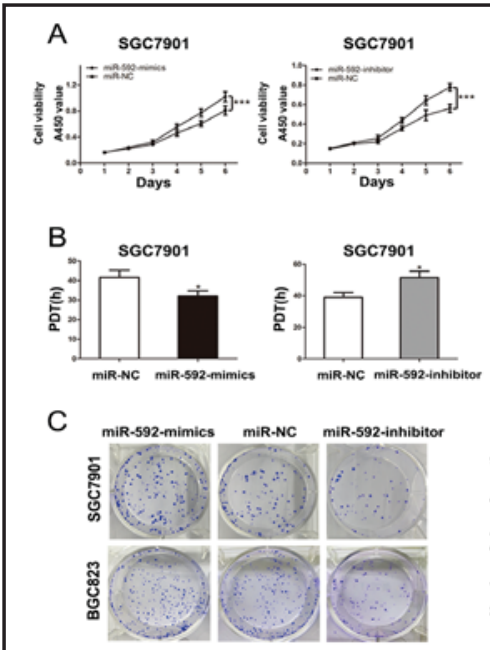

D
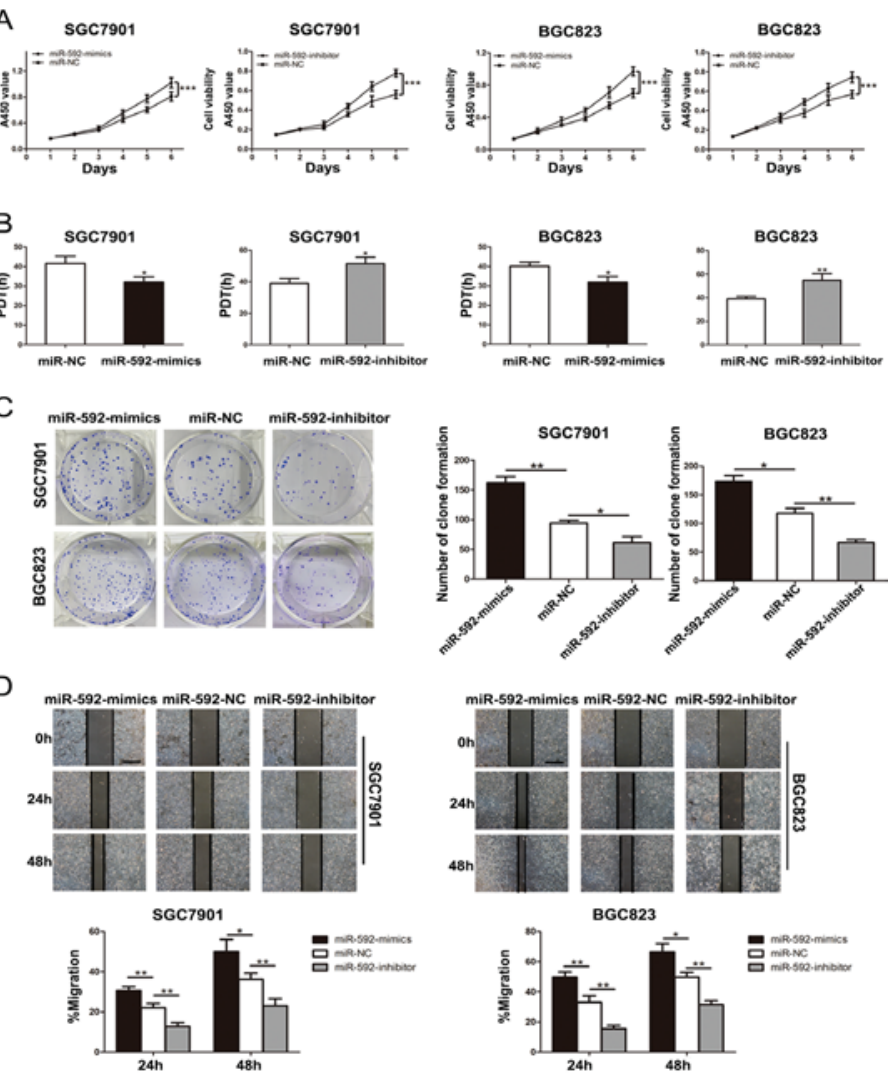

E
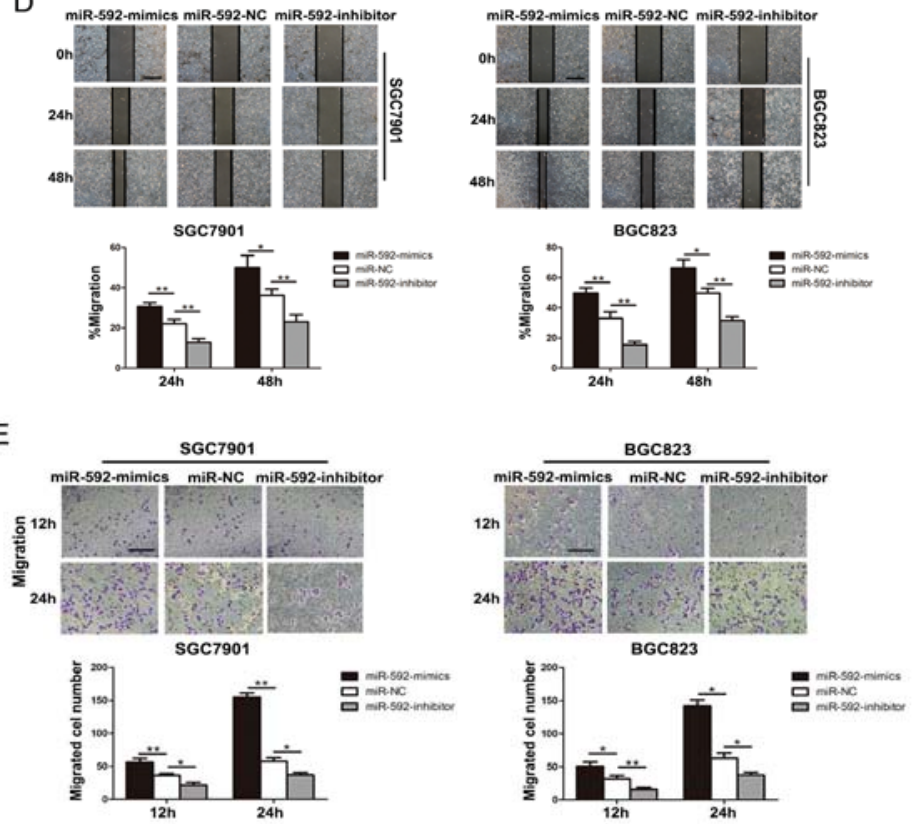

$\mathrm{F}$
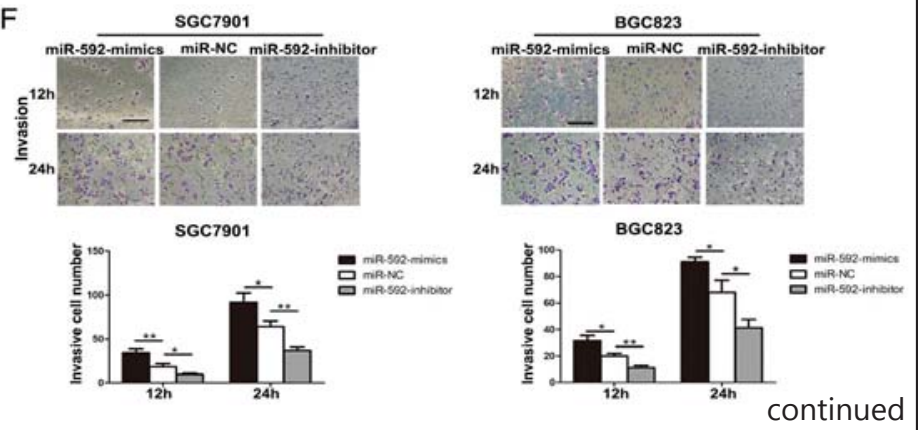

miR-592 promotes the growth of GC in vivo

To investigate the effect of miR-592 on proliferation in vivo, cells stably transfected with miR-592-mimics or miR-592-inhibitor were injected into the flanks of nude mice, with cells transfected with miR-NC used as a negative control. Four weeks after inoculation, xe- 


\section{Cellular Physiology and Biochemistry}

Cell Physiol Biochem 2018;47:1465-1481

He et al.: MiR-592 Promotes PI3K/AKT and MAPK/ERK Signaling by Inhibiting Spry2 in

nografted tumors were harvested from the euthanized mice. The volume and weight of implanted tumors were dramatically increased in the miR-592-mimics group and decreased in the miR-592-inhibitor group compared with the negative control group. In addition, the calculated doubling time confirmed that ectopic miR-592 could promote the growth of GC (Fig. 2G-J). Moreover, qRT-PCR analysis revealed upregulated miR592 expression in the miR592-mimics group compared with the control group, but reduced expression in the miR592-inhibitor group (Fig. 2K). Taken together, miR-592 has a positive effect on the tumorigenicity of GC in vivo.

Spry2 is a predicted target of $\mathrm{miR}-592$

TargetScan (http://www. targetscan.org/vert_71/), miRNAMap ( (https://cm.jefferson.

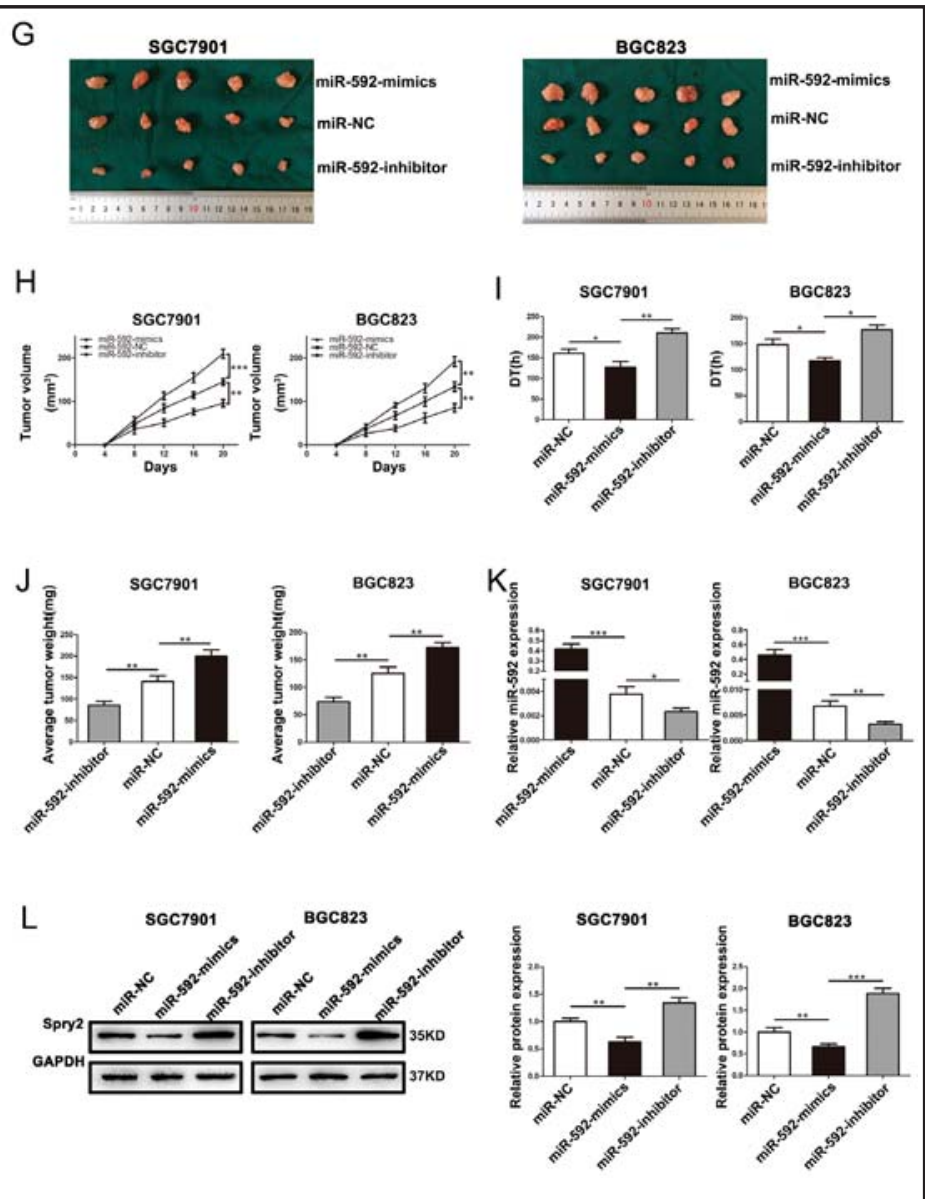

edu/rna22/Precomputed/) were applied to predict the targets of miR-592. According to the intersection of the three computational prediction results, we found that Spry2, a known tumor suppressor, was a potential target of miR-592.

Spry2 is downregulated in GC tissues and cells

To explore the relationship between miR-592 and Spry2, we determined the expression of Spry2 in 70 GC tissues and adjacent normal tissues with qRT-PCR. As shown in Fig. 3A, compared with the paired adjacent normal tissues, the relative expression of miR-592 was clearly reduced in primary tumor tissues. In addition, we examined the Spry2 protein expression in six paired GC specimens through western blot. As shown in Fig. 3B, the immunohistochemical expression of Spry2 was lower in GC tissues than in the adjacent normal tissues. Spry2 expression was consistently downregulated in GC specimens (Fig. 3C). We also found that the miR-592 expression level was negatively correlated with Spry2 expression (Fig. 3D). We next detected the Spry2 expression in GC and GES-1 cells with qRTPCR and western blot. As shown in Fig. 3E and F, the relative expression of Spry2 at both mRNA and protein levels was distinctly lower in GC cells than in GES-1 cells. In addition, we conducted a correlation analysis between the Spry2 expression level and the clinicopathologic characteristics of GC patients (Table 1). Low Spry2 expression was correlated with tumor size, histological type, and lymph node metastasis. All of these results suggested that Spry2 might be a target of miR-592 in GC and play a role in tumor inhibition.

Spry2 is a direct target of miR-592 in GC

Dual-luciferase reporter assays were performed to further test whether Spry2 is a direct target of miR-592 in GC. We cloned wild-type (WT) and mutant-type (MUT) Spry2 


\section{Cellular Physiology Cell Physiol Biochem 2018;47:1465-1481 \begin{tabular}{c|c|c|} 
DOI: 10.1159/000490839 & ( 2018 The Author(s). Published by S. Karger AG, Basel \\
\hline
\end{tabular}

He et al.: MiR-592 Promotes PI3K/AKT and MAPK/ERK Signaling by Inhibiting Spry2 in GC

Fig. 3. Spry2 was downregulated in GC tissues and cells and was confirmed to be the direct target of miR-592. (A) The expression level of Spry2 was determined in 70 pairs of human GC tissues and adjacent normal tissues by qRT-PCR. (B) Spry2 protein level was detected by western blot in 6 pairs of GC and non-GC tissues. GAPDH was served as the internal reference. (C) Immunohistochemistry staining was used to determine the protein level of Spry2 in GC tissues and adjacent tissues. (D) The correlation was analyzed between the expression level of miR-592 and mRNA level of Spry2. (E, F) The expression of Spry2 in GC cells and GES-1 were detected by qRT-PCR and western blot respectively. (G) Dual luciferase reporter assay was conducted to

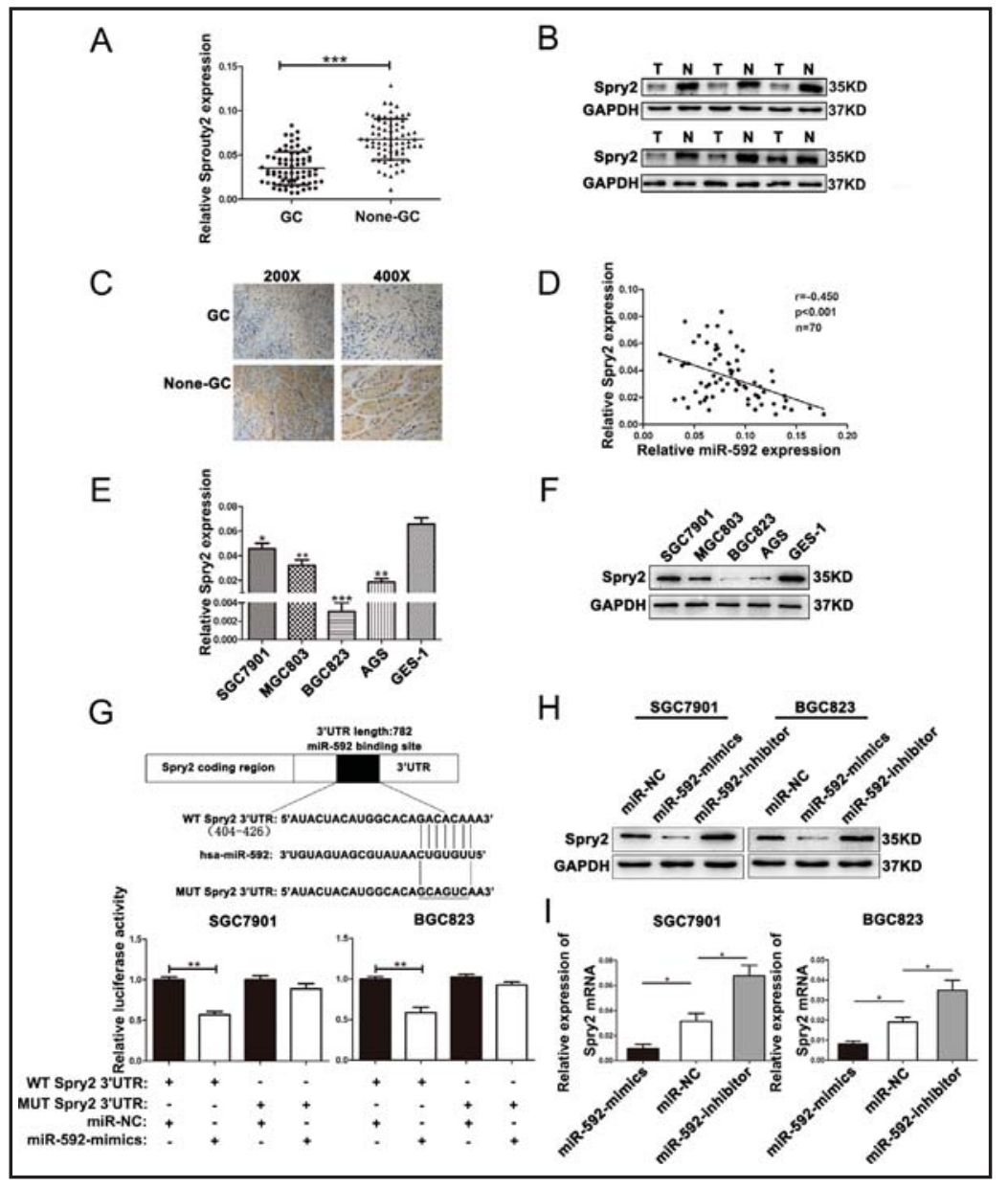
confirm whether miR-592 directly bind to the 3'UTR of Spry2. Change of luciferase activity was analyzed in SGC7901 and BGC823 which were co-transfected with miR-592-mimics or negative control and the pGL3WT-Spry2 3'-UTR or pGL3-MUT-Spry2 3'-UTR. (H) Effects of miR-592 alteration on expression level of spry2 protein in GC cells by western blot. (I) The expression level of spry2 mRNA in GC cells after miR-592 alteration by qRT-PCR. ${ }^{*} \mathrm{P}<0.05,{ }^{* *} \mathrm{P}<0.01,{ }^{* * *} \mathrm{P}<0.001$. The data expressed as the mean $\pm \mathrm{SD}$.

Table 1. Expression of miR592 and Spry2 in human gastric cancer according to patients' clinicopathological characteristics. ${ }^{*} P<0.05$ $\quad{ }^{* *} P<\quad 0.01 \quad$ Statistically significant difference

\begin{tabular}{|c|c|c|c|c|c|c|c|}
\hline \multirow[t]{2}{*}{ Characteristics } & \multirow[t]{2}{*}{ Number } & \multicolumn{2}{|c|}{ miR-592 expression } & \multicolumn{2}{|c|}{$\mathrm{p}$-value } & \multirow{2}{*}{$\begin{array}{c}\text { Spry2 expression } \\
\text { Low group }\end{array}$} & \multirow[t]{2}{*}{$\mathrm{p}$-value } \\
\hline & & High group & Low group & & group & & \\
\hline \multicolumn{8}{|l|}{ Age(years) } \\
\hline$<60$ & 28 & 12 & 16 & 0.558 & 11 & 17 & 0.622 \\
\hline$\geq 60$ & 42 & 21 & 21 & & 19 & 23 & \\
\hline \multicolumn{8}{|l|}{ Gender } \\
\hline Male & 38 & 17 & 21 & 0.660 & 15 & 23 & 0.533 \\
\hline Female & 32 & 16 & 16 & & 15 & 17 & \\
\hline \multicolumn{8}{|l|}{$\operatorname{Size}(\mathrm{cm})$} \\
\hline$<3$ & 33 & 10 & 23 & $0.008^{* *}$ & 19 & 14 & $0.019 *$ \\
\hline$\geq 3$ & 37 & 23 & 14 & & 11 & 26 & \\
\hline \multicolumn{8}{|l|}{ Histological type } \\
\hline Well-moderately & 23 & 6 & 17 & $0.014^{*}$ & 14 & 9 & $0.033^{*}$ \\
\hline Poorly-signet & 47 & 27 & 20 & & 16 & 31 & \\
\hline \multicolumn{8}{|l|}{ Stage } \\
\hline I / II & 31 & 13 & 18 & 0.436 & 13 & 18 & 0.890 \\
\hline III/IV & 39 & 20 & 19 & & 17 & 22 & \\
\hline \multicolumn{8}{|l|}{$\mathrm{T}$ grade } \\
\hline $\mathrm{T} 1+\mathrm{T} 2$ & 27 & 11 & 16 & 0.395 & 14 & 13 & 0.228 \\
\hline $\mathrm{T} 3+\mathrm{T} 4$ & 43 & 22 & 21 & & 16 & 27 & \\
\hline \multicolumn{8}{|c|}{ Lymph node metastasis } \\
\hline Absent(N0) & 29 & 8 & 21 & $0.006^{* *}$ & 17 & 12 & $0.025^{*}$ \\
\hline Present(N1-N3) & 41 & 25 & 16 & & 13 & 28 & \\
\hline
\end{tabular}




\section{Cellular Physiology \\ Cell Physiol Biochem 2018;47:1465-1481 \\ \begin{tabular}{ll|l} 
DOI: 10.1159/000490839 & $\begin{array}{l}\text { () } 2018 \text { The Author(s). Published by S. Karger AG, Base } \\
\text { www.karger.com/cpb }\end{array}$ \\
\cline { 2 - 4 }
\end{tabular} \\ He et al.: MiR-592 Promotes PI3K/AKT and MAPK/ERK Signaling by Inhibiting Spry2 in}

$\mathrm{GC}$

Fig. 4. Effects of ectopic Spry2 expression on GC proliferation, migration and invasion. (A) Western blot was used to measure the expression of Spry2 transfected with Spry2 lentivirus or vector. (B, C) Cell growth rate and proliferation was detected by CCK8 assay and PDT. (D) The results of colony formation in two GC cells. (E) The change of cell migration was assessed by wound healing assay, scale bar: $400 \mu \mathrm{m}$. (F) Transwell assay was carried out to verify the effects of Spry2 alteration on migratory and invasive ability of GC cells scale bar: $200 \mu \mathrm{m} . * \mathrm{P}<0.05$, ** $\mathrm{P}<0.01, * * * \mathrm{P}<0.001$. The data expressed as the mean \pm SD.
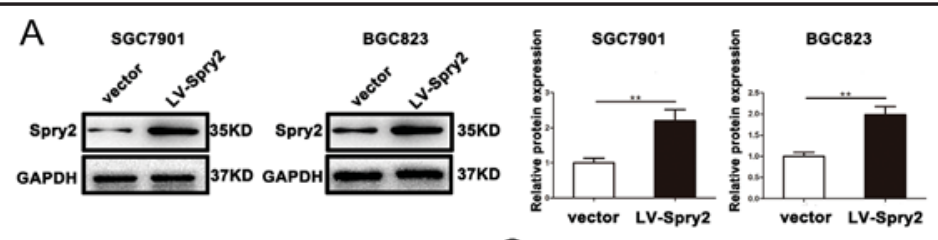

B

C sGc7901
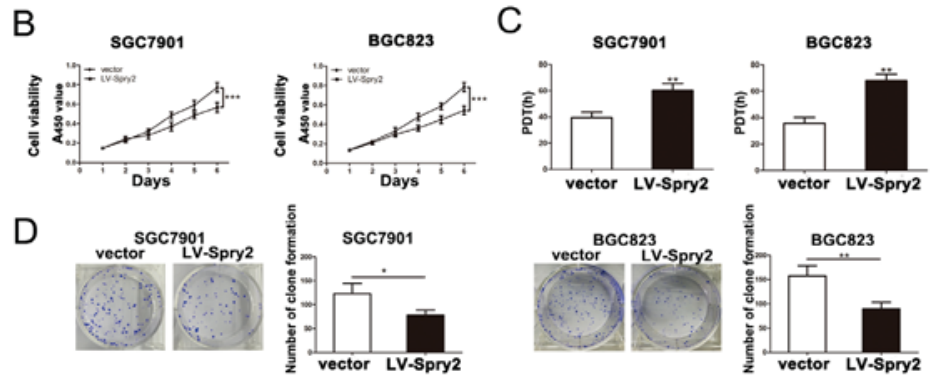

E
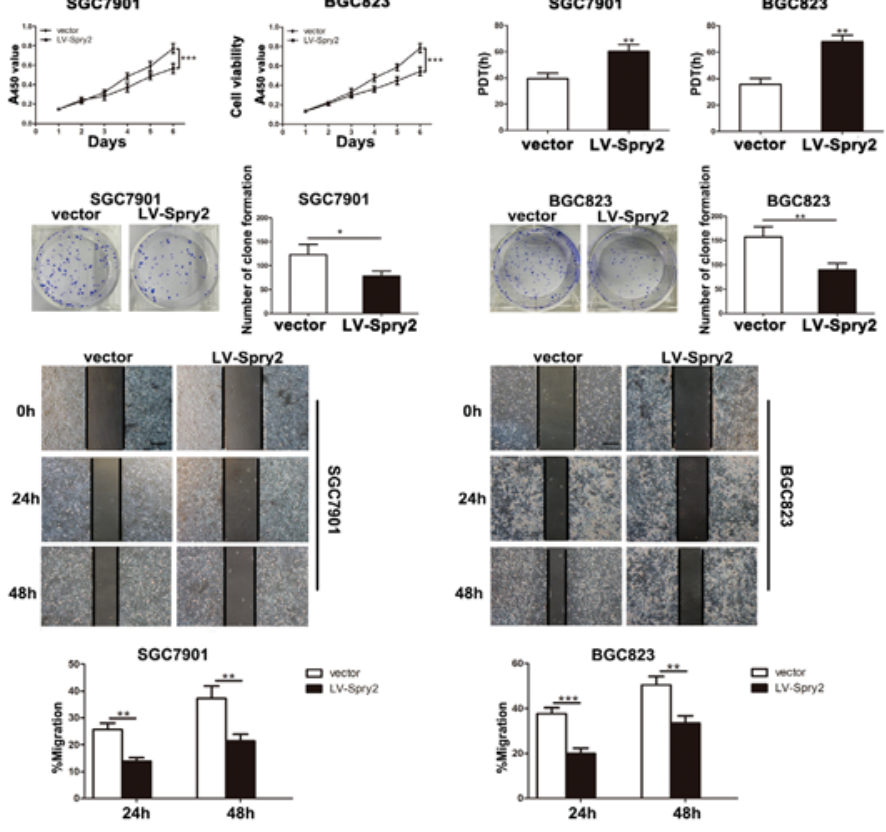

$\mathrm{F}$
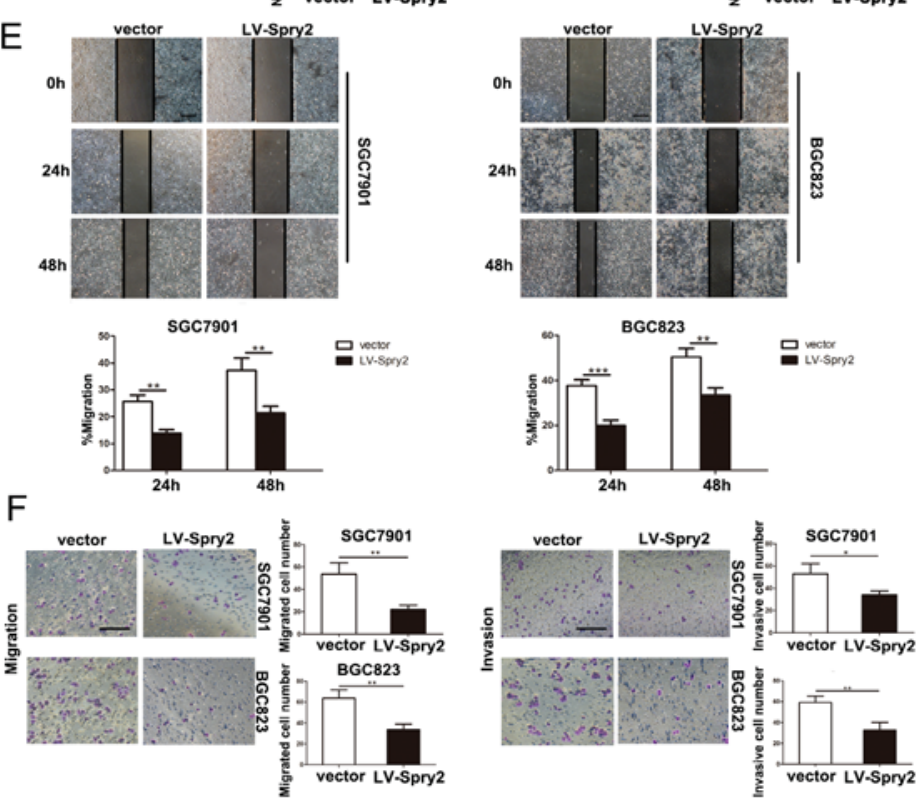

3'UTR sequences (the former containing the original binging site and the latter containing site-directed mutations) into the reporter plasmid. miR-592-mimics and the pGL3-WTSpry2 3'UTR were cotransfected into SGC7901 and BGC823 cells, with the results indicating that overexpression of miR-592 could decrease luciferase activity compared with the control group. However, there was no evident change in luciferase activity in the same cells cotransfected with pGL3-MUT-Spry2 3'UTR and miR-592-mimics, confirming that Spry2 is a direct target of miR-592 (Fig. 3G).

\section{miR-592 represses Spry2 protein expression via mRNA degradation}

To study the explicit mechanism by which miR-592 regulated Spry2, we performed western blot to analyze Spry2 protein levels. In contrast to the control, Spry2 protein levels in SGC7901 and BGC823 cells were clearly reduced after transfection with miR-592mimics and elevated after transfection with miR-592-inhibitor (Fig. 3H). In addition, after transfection with miR-592-mimics and miR-592-inhibitor, qRT-PCR was used to determine whether there was a difference in Spry2 mRNA levels in the two cell lines compared with the negative control group. As shown in Fig. 3I, the relative expression of Spry 2 mRNA in cells transfected with miR-592-mimics was lower than in the control, and the inverse result was obtained with miR-592-inhibitor. The relative protein expression of Spry2 from xenografted tumors also confirmed that upregulated miR-592 expression could reduce Spry2 protein 


\section{Cellular Physiology \\ Cell Physiol Biochem 2018;47:1465-1481

\begin{tabular}{ll|l} 
aOI: 10.1159/000490839 & $\begin{array}{l}\text { } 2018 \text { The Author(s). Published by S. Karger AG, Basel } \\
\text { www.karger.com/cpb }\end{array}$ \\
\hline
\end{tabular}

Fig. 5. Overexpressed Spry2 could partially reverse the facilitative effects of miR592 on GC cell. The rescue experiments were performed to verify the change of biological function in SGC7901 and BGC823 transfected with miR-592-mimics or negative control and Spry2 lentivirus or vector without its 3'UTR. (A, B) Cell growth rate was detected and calculated by CCK8 assay and PDT. (C) The results of colony formation in two GC cells. (D) The change of cell migration was assessed by wound healing assay, scale bar: $400 \mu \mathrm{m}$. (E) Transwell assay was conducted to verify the effects of Spry2 alteration on migration and invasion of GC cells, scale bar: $200 \mu \mathrm{m}$. (F) The expression level of Spry2 protein was verified by western blot. * $\mathrm{P}<0.05$, ** $\mathrm{P}$ $<0.01, * * * \mathrm{P}<0.001$. The data expressed as the mean \pm SD.
A

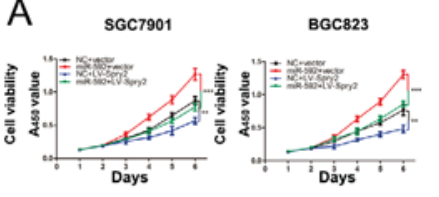

C

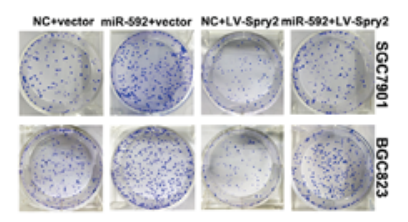

D

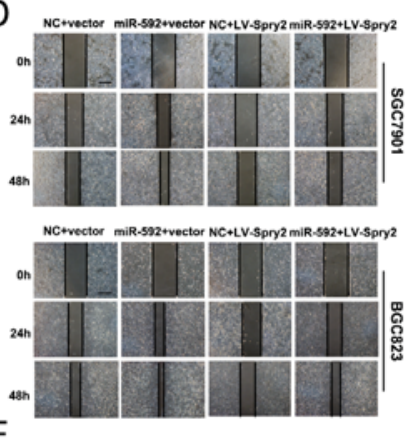

E
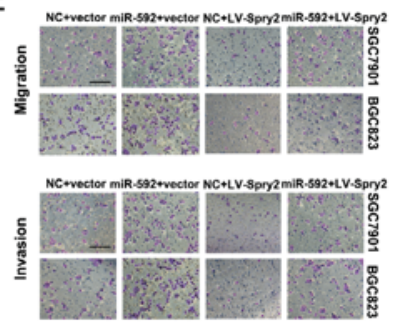

$\mathrm{F}$

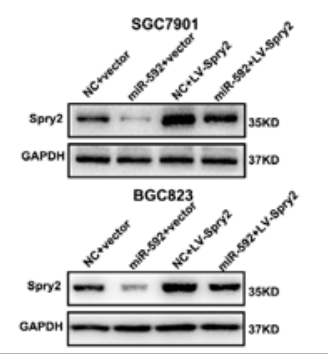

B
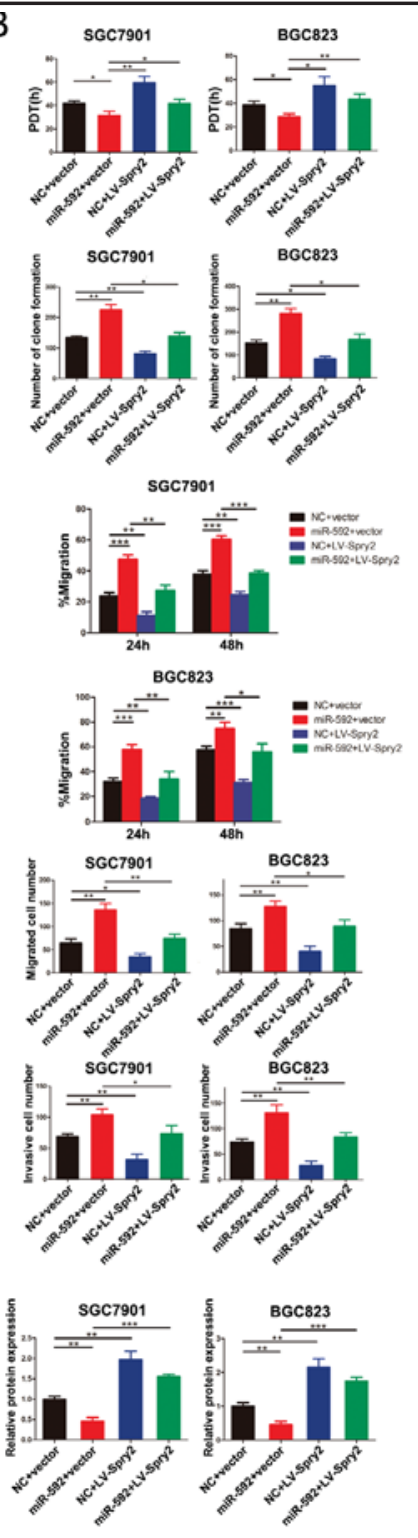

expression compared with the control group (Fig. 2L). Thus, we concluded that miR-592 represses Spry2 protein expression via mRNA degradation.

miR-592 promotes GC cell proliferation, migration, and invasion by targeting Spry2

We have shown that miR-592 overexpression promoted proliferation, migration, and invasion in GC cells and suppressed Spry2 protein expression by directly binding to the 3'UTR of Spry 2 and triggering its mRNA degradation. In contrast, miR-592 downregulation had the opposite effects. To further determine whether miR-592 promoted the progression and development of GC by modulating Spry2, we first upregulated the expression of Spry2 in SGC7901 and BGC823 cells; the transfection efficacy was verified by western blot (Fig. 4A). Through CCK8, PDT, colony formation, wound-healing, and Transwell assays, we found that overexpressed Spry2 could inhibit the proliferation, migration, and invasion of GC cells (Fig. 4B-F). Next, the two cell lines were cotransfected with miR-592-mimics and LV-Spry2. In conjunction with the above assays, we performed the appropriate rescue experiments and demonstrated that ectopic expression of Spry 2 could reverse the promotion of proliferation, migration, and invasion induced by miR-592 overexpression in SGC7901 cells. The same 
He et al.: MiR-592 Promotes PI3K/AKT and MAPK/ERK Signaling by Inhibiting Spry2 in GC

Fig. 6. $\operatorname{miR}-592$ induced EMT and positively regulated PI3K/AKT and MAPK/ERK signaling pathway in GC cells by downregulation of Spry2. (A) Western blot showed the change of core biomarkers such as E-cadherin, Vimentin, N-cadherin in EMT and ERK, p-ERK, AKT, p-AKT in cells transfected with miR-NC, miR592-mimics and miR-592-inhibitor. (B) The expression of these proteins were detected by western blot after the restoration of Spry2.

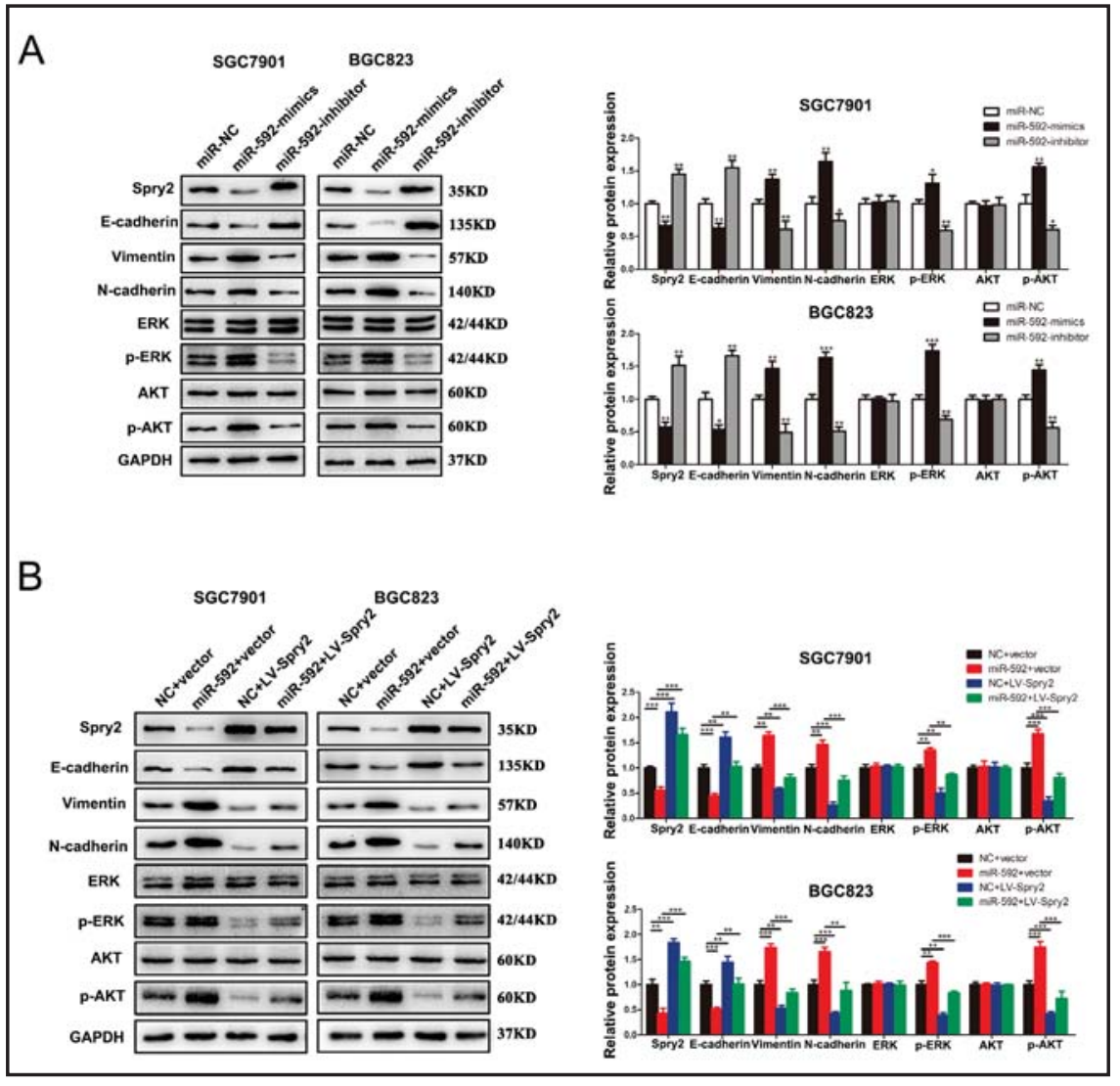

effects were seen in BGC823 cells (Fig. 5A-E). Spry2 protein expression was confirmed by western blot in transfected cells (Fig. 5F). These findings verified that restoration of Spry2 expression could counteract the effects of miR-592-mimics, which further demonstrated that miR-592 promotes proliferation, migration, and invasion in GC cells by directly targeting Spry2.

Overexpression of miR-592 induces the EMT via Spry2

The EMT is a vital biological process in which malignant cells acquire migratory and invasive abilities, and we have confirmed that miR-592 promoted migration and invasion in GC cells by targeting Spry2. Hence, we wondered if miR-592 might play a role in the EMT of GC cells and thus used western blotting to examine the expression of characteristic biomarkers of this process, such as E-cadherin, vimentin, and N-cadherin. As shown in Fig. 6A, compared with miR-NC, SGC7901 and BGC823 cells transfected with miR-592-mimics revealed decreased expression of E-cadherin and increased expression of vimentin and $\mathrm{N}$-cadherin; this change was partially counteracted by cotransfection with LV-Spry2 (Fig. $6 \mathrm{~B}$ ). This finding indicated that overexpression of miR-592 could induce the EMT via Spry2 in GC cells.

miR-592 promotes the PI3K/AKT and MAPK/ERK signaling pathway in GC cells by targeting Spry2

The classic PI3K/AKT and MAPK/ERK signaling pathways modulate the progression of various cancers by affecting their proliferation, migration, and invasion [24-26]. Spry2 has also been confirmed to be a suppressive regulator of the PI3K/AKT and/or MAPK/ERK signaling pathways [27-29]. Therefore, we examined the expression of ERK, p-ERK, AKT, and p-AKT with western blot to determine whether miR-592 participates in the activation of PI3K/ AKT and/or MAPK/ERK signaling pathways. As shown in Fig. 6A, miR-592 overexpression 


\section{Cellular Physiology Cell Physiol Biochem 2018;47:1465-1481 and Biochemistry Published online: June 25, $2018 \quad$\begin{tabular}{c|c} 
D 2018 The Authors. \\
www.karger.com/cpb
\end{tabular}}

He et al.: MiR-592 Promotes PI3K/AKT and MAPK/ERK Signaling by Inhibiting Spry2 in GC

significantly increased p-ERK and p-AKT in GC cells compared with the control group, with knockdown of miR-592 showing the opposite effects. No difference was observed in the expression of ERK and AKT. In addition, this effect was partially blocked by upregulation of Spry2 expression in cells transfected with miR-592-mimics, which indicated that Spry2 functioned as a suppressor of both the PI3K/AKT and MAPK/ERK signaling pathways (Fig. 6B). All of these results indicated that the mechanism by which miR-592 facilitates the proliferation, migration, and invasion of GC cells is associated with activation of the PI3K/ AKT and MAPK/ERK signaling pathways via suppression of Spry2.

\section{Discussion}

Dysregulation of miRNAs is involved in the development and progression of various human malignancies. For example, miR-3151 promotes cell proliferation and decreases apoptosis in malignant melanoma and papillary thyroid cancer by targeting TP53 [30], miR224 promotes tumor progression in non-small cell lung cancer by activating ERK signaling [31], and miR-584-5p inhibits proliferation in GC by targeting WWP1 [32]. A few studies have reported that miR-592 is aberrantly expressed and plays bidirectional roles in different malignancies such as colorectal cancer and hepatocellular carcinoma [12, 13, 15]. However, the impact of miR-592 on GC and the potential molecular mechanism remained unclear. In this study, we propose a novel role for miR-592 in GC cells, finding that miR-592 was highly expressed in both GC cells and clinical specimens, results that were consistent with the results in TCGA database. According to the cell function experiments, overexpressed miR592 promoted proliferation, migration, invasion, and the EMT in vitro and tumorigenicity in vivo, suggesting that miR-592 may be a valid prognostic indicator for GC patients. In addition, our research confirmed that miR-592 serves as a tumor facilitator in GC through the PI3K/ AKT and MAPK/ERK signaling pathways.

The potential target of miR-592 was predicted by bioinformatics analysis. Of the putative targets, Spry2, which has three homologues, drew our attention. The Spry family (spry1-4) was first identified in Drosophila, where it acts as an inhibitor of fibroblast growth factor in tracheal branching morphogenesis [17]. It was also noted for regulating the receptor tyrosine kinase (RTK)-mediated MAPK/ERK signaling pathway because it has a cysteine-rich domain carboxyl-terminal that inhibits RTK signaling proteins [33]. Spry2 has been linked to fibrosis, angiogenesis, and carcinogenesis [33-35]. Spry2 was mainly identified as a suppressor in various malignances. For example, Spry2 inhibits GC progression by antagonizing the activation of RAS/ERK [23]. In addition, Spry2 can be targeted and modulated by several miRNAs. Shukla et al. reported that Spry2 was suppressed by miR-21 and negatively regulated BCR-mediated MAPK-ERK signaling in chronic lymphocytic leukemia [36]. miR-27b may promote the migration and invasion of hepatocellular carcinoma cells, at least partially by suppressing Spry2 expression [37].

In our study, we confirmed the relative expression of Spry2 in GC tissues and cells, showing that Spry2 expression was much lower in GC tissues than in paired normal tissues and GES-1 cells. By analyzing clinicopathological characteristics, we determined that Spry2 expression was correlated with tumor size, histological type, and lymph node metastasis. In addition, dual-luciferase reporter assays showed that miR-592 suppressed Spry2 by directly binding to its 3'UTR and that overexpressed miR-592 could suppress Spry2 expression by degrading Spry 2 mRNA. In addition, restoration of Spry2 partially counteracted the inductive effects of miR-592-mimics on proliferation, migration, and invasion. In summary, our study demonstrated the ability of miR-592 to promote GC in a manner that is modulated by Spry2 inhibition.

The EMT, the biological process by which epithelial cells are transformed into stromal cells by a specific process, plays a crucial role in cancer progression and metastasis. The EMT is characterized by a series of reversible molecular and phenotypic alterations and increased cell motility that promote the biological aggressiveness of malignant cells, such as invasion and metastasis [38, 39]. Recent accumulating evidence has indicated that miRNAs 


\section{Cellular Physiology Cell Physiol Biochem 2018;47:1465-1481 \\ \begin{tabular}{ll|l} 
DOI: 10.1159/000490839 & $\begin{array}{l}\text { () } 2018 \text { The Author(s). Published by S. Karger AG, Base } \\
\text { www.karger.com/cpb }\end{array}$ \\
\hline
\end{tabular}}

GC

are implicated in the EMT. Zhang et al. reported that miRNA-148a suppresses the EMT and metastasis of hepatoma cells by targeting Met/Snail signaling [40]. Chen et al. showed that miR-1236 regulated hypoxia-induced EMT and inhibited the migratory and invasive activity of tumor cells by suppressing SENP1 and HDAC3 [41]. In the present study, we determined that overexpressed miR-592 could promote the EMT by dramatically reducing the expression of E-cadherin while increasing the levels of $\mathrm{N}$-cadherin and vimentin. This effect was partly reversed by cotransfection of cells with Spry 2 and miR-592-mimics. Together, these findings indicated that miR-592 induces the EMT by targeting Spry2.

However, the role played by Spry2 in the EMT is controversial. So et al. reported that overexpression of Spry2 could attenuate the EGF-induced E-cadherin downregulation and then reduce EGF-induced cell invasion. Moreover, they observed a positive correlation between Spry2 and E-cadherin protein levels in high-grade serous ovarian carcinoma tissues [19]. In addition, inhibition of miR-21, which targets Spry2, can attenuate hepatocyte EMT and Spry2 represses the epithelial phenotype of colon carcinoma cells via upregulation of ZEB1 mediated by ETS1 and miR-200/miR-150 [34, 35]. Nevertheless, Zhang et al. have confirmed an atypical role played by sprouty as an oncogene by driving the EMT in colorectal cancer, which contradicts our findings that overexpressed Spry2 could inhibit the EMT in GC [22]. Considering the tissue specificity of gene expression, which means that the expression levels of the same gene are different at the same developmental stages of different tissues and organs, patterns of expression and regulation could also vary among different tissues. In addition, because one gene could be regulated by means of DNA methylation and histone modifications, the combined biological effects are primarily influenced by the specific genetic background of the types of tumors or cells in which the Spry2 is expressed. Thus, the seemly distinct functions of Spry2 in different cancer types reflect the intrinsic diversities and complexities of tumor biology.

The PI3K/AKT and MAPK/ERK signaling pathways are closely associated and participate in multiple cellular processes, including growth, proliferation, differentiation, migration, and the EMT [42-46]. Although Spry2 is known for its suppressive role in the MAPK/ERK signaling pathway, FGFR2-induced promotion of progression of GC is antagonized by Spry2 via inhibition of ERK phosphorylation [23]. Loss of Spry2 can also activate the PI3K/AKT pathway through interaction with the ErbB system in prostate cancer [47]. How Spry2 can influence the two signaling pathways could be illustrated by one potential molecular mechanism: Spry proteins interact with GRB2, which is the SH2/SH3 domain-containing adapter protein, and can link to and activate the RTK implicated in both pathways. Accordingly, the gain or loss of Spry2 allows regulation of these two classic oncogenic pathways $[27,48]$. In the present study, miR-592 was shown to modulate the PI3K/AKT and MAPK/ERK signaling pathways by directly targeting Spry2. Overexpressed miR-592 promoted the phosphorylation and activation of AKT and ERK while downregulated miR-592 exerted the opposite effect.

Although it seems that the molecular mechanisms exploited by miRNAs are quite unequivocal, there have been other interesting findings in this field. Adjacent miRNAs could constitute an miRNA cluster, which regulates the common target and the signaling pathways. Foxo1 can be downregulated by the miR-183-96-182 cluster, which promotes T helper 17 cell pathogenicity [49]. Methylation of miRNA promoters can itself also account for the aberrant expression of miRNA and be associated with cancer susceptibility [50]. In addition, miR-122 can downregulate the expression of miR-21 by directly binding to the pri-miR-21 sequence, which influences the process of the RNase III Drosha [51]. Taken together, these new findings and developments reflect the diversity and complexity of miRNA regulation, suggesting that the regulation of miR-592 is its diverse and complicated.

Therapies based on miRNAs have gradually moved from the theoretical realm to clinical application. A mimic of miR-34, which acts as a tumor suppressor, has reached phase I clinical trials for the treatment of cancer. In addition, anti-miRNAs targeted at miR-122 have reached phase II trials for hepatitis treatment [52]. All of these advances in this field have increased our confidence in the potential of miRNA-targeted therapeutics. Nonetheless, validation of the feasibility and safety of an miR-592-based therapeutic is urgently needed. 


\section{Cellular Physiology Cell Physiol Biochem 2018;47:1465-1481 \\ \begin{tabular}{ll|l} 
DOI: 10.1159/000490839 & $\begin{array}{l}\text { ( ) } 2018 \text { The Author(s). Published by S. Karger AG, Base } \\
\text { www.karger.com/cpb }\end{array}$ \\
\cline { 2 - 3 }
\end{tabular} \\ He et al.: MiR-592 Promotes PI3K/AKT and MAPK/ERK Signaling by Inhibiting Spry2 in GC}

This is the first study to demonstrate that miR-592 functions as an oncogene in GC via the following new findings: miR-592 is frequently upregulated in GC tissues and cell lines; miR-592 promotes proliferation, migration, and invasion and induces the EMT through the PI3K/AKT and MAPK/ERK signaling pathways in GC cells; a downstream target gene of miR592 is Spry2; and the effects of miR-592 are counteracted by Spry2 overexpression. However, we realize that our study has certain limitations and shortcomings. For instance, a single miRNA may control and target multiple genes and one single gene can also be regulated by several miRNAs. In addition to the advances in this field mentioned above, we have not ruled out the potential role of other genes targeted by miR-592 and related signaling pathways in these processes, which could further explain the potential mechanisms. Thus, protocol optimization and further study are required.

In summary, our study showed that miR-592 was correlated with tumor size, histological type, and lymph node metastasis and that it promoted proliferation, migration, invasion, and the EMT by inhibiting Spry2-mediated PI3K/AKT and MAPK/ERK signaling pathways. These findings indicate that miR-592 could be a potential therapeutic target in GC.

\section{Acknowledgements}

This work was financially supported by the Natural Science Foundation of Jiangsu Province (grant no. BK20171505), the "Medical ZhongDianRenCai Project" of Jiangsu Province (grant no. RC2011059), and Jiangsu Provincial 333 Project (grant no. BRA2013280 (RS13).

\section{Disclosure Statement}

The authors declare to have no conflict of interests.

\section{References}

1 Torre LA, Bray F, Siegel RL, Ferlay J, Lortet-Tieulent J, Jemal A: Global cancer statistics, 2012. CA Cancer J Clin 2015;65:87-108.

2 Chen W, Zheng R, Baade PD, Zhang S, Zeng H, Bray F, Jemal A, Yu XQ, He J: Cancer statistics in China, 2015 CA Cancer J Clin 2016;66:115-132.

3 Shmulevich I: Large-scale molecular characterization and analysis of gastric cancer. Chin J Cancer 2014;33:369-370.

4 Wadhwa R, Song S, Lee JS, Yao Y, Wei Q, Ajani JA: Gastric cancer-molecular and clinical dimensions. Nat Rev Clin Oncol 2013;10:643-655.

5 Zhang M, Du X: Noncoding RNAs in gastric cancer: Research progress and prospects. World J Gastroenterol 2016;22:6610-6618.

6 Bartel DP: MicroRNAs: genomics, biogenesis, mechanism, and function. Cell 2004;116:281-297.

7 Bartel DP: MicroRNAs: target recognition and regulatory functions. Cell 2009;136:215-233.

8 Irmak-Yazicioglu MB: Mechanisms of MicroRNA Deregulation and MicroRNA Targets in Gastric Cancer. Oncol Res Treat 2016;39:136-139.

-9 Kumar AS, Jagadeeshan S, Pitani RS, Ramshankar V, Venkitasamy K, Venkatraman G, Rayala SK: SnailModulated MicroRNA 493 Forms a Negative Feedback Loop with the Insulin-Like Growth Factor 1 Receptor Pathway and Blocks Tumorigenesis. Mol Cell Biol 2017;37:

10 Yuan D, Xu J, Wang J, Pan Y, Fu J, Bai Y, Zhang J, Shao C: Extracellular miR-1246 promotes lung cancer cell proliferation and enhances radioresistance by directly targeting DR5. Oncotarget 2016;7:32707-32722.

11 Kedmi M, Ben-Chetrit N, Korner C, Mancini M, Ben-Moshe NB, Lauriola M, Lavi S, Biagioni F, Carvalho S, Cohen-Dvashi H, Schmitt F, Wiemann S, Blandino G, Yarden Y: EGF induces microRNAs that target suppressors of cell migration: miR-15b targets MTSS1 in breast cancer. Sci Signal 2015;8:ra29.

12 Fu Q, Du Y, Yang C, Zhang D, Zhang N, Liu X, Cho WC, Yang Y: An oncogenic role of miR-592 in tumorigenesis of human colorectal cancer by targeting Forkhead Box 03A (FoxO3A). Expert Opin Ther Targets 2016;20:771-782. 


\section{Cellular Physiology Cell Physiol Biochem 2018;47:1465-1481 \\ \begin{tabular}{ll|l} 
and Biochemistry & Published online: June 25, 2018 & $\begin{array}{l}\text { () } 2018 \text { The Author(s). Published by S. Karger AG, Basel } \\
\text { www.karger.com/cpb }\end{array}$ \\
\cline { 2 - 3 }
\end{tabular}}

He et al.: MiR-592 Promotes PI3K/AKT and MAPK/ERK Signaling by Inhibiting Spry2 in GC

13 Liu M, Zhi Q, Wang W, Zhang Q, Fang T, Ma Q: Up-regulation of miR-592 correlates with tumor progression and poor prognosis in patients with colorectal cancer. Biomed Pharmacother 2015;69:214-220.

14 Lv Z, Rao P, Li W: MiR-592 represses FOXO3 expression and promotes the proliferation of prostate cancer cells. Int J Clin Exp Med 2015;8:15246-15253.

15 Wang W, Zhang H, Tang M, Liu L, Zhou Z, Zhang S, Wang L: MicroRNA-592 targets IGF-1R to suppress cellular proliferation, migration and invasion in hepatocellular carcinoma. Oncol Lett 2017;13:3522-3528.

-16 Jia YY, Zhao JY, Li BL, Gao K, Song Y, Liu MY, Yang XJ, Xue Y, Wen AD, Shi L: miR-592/WSB1/HIF-1alpha axis inhibits glycolytic metabolism to decrease hepatocellular carcinoma growth. Oncotarget 2016;7:3525735269.

17 Hacohen N, Kramer S, Sutherland D, Hiromi Y, Krasnow MA: sprouty encodes a novel antagonist of FGF signaling that patterns apical branching of the Drosophila airways. Cell 1998;92:253-263.

18 Yim DG, Ghosh S, Guy GR, Virshup DM: Casein kinase 1 regulates Sprouty2 in FGF-ERK signaling. Oncogene 2015;34:474-484.

19 So WK, Cheng JC, Fan Q, Wong AS, Huntsman DG, Gilks CB, Leung PC: Loss of Sprouty2 in human high-grade serous ovarian carcinomas promotes EGF-induced E-cadherin down-regulation and cell invasion. FEBS Lett 2015;589:302-309.

20 Li P, Tao L, Yang J, Cai H, Ju X, Li J, Shao P, Cao Q, Qin C, Meng X, Yin C: Sprouty2 is associated with prognosis and suppresses cell proliferation and invasion in renal cell carcinoma. Urology 2013;82:253 e251-257.

-21 Sutterluty H, Mayer CE, Setinek U, Attems J, Ovtcharov S, Mikula M, Mikulits W, Micksche M, Berger W: Down-regulation of Sprouty2 in non-small cell lung cancer contributes to tumor malignancy via extracellular signal-regulated kinase pathway-dependent and -independent mechanisms. Mol Cancer Res 2007;5:509-520.

22 Zhang Q, Wei T, Shim K, Wright K, Xu K, Palka-Hamblin HL, Jurkevich A, Khare S: Atypical role of sprouty in colorectal cancer: sprouty repression inhibits epithelial-mesenchymal transition. Oncogene 2016;35:31513162.

-23 Xu Y, Yang X, Li Z, Li S, Guo S, Ismail S, Liu H, Huang Z, Zhang Z, Chen Y, Sun Q: Sprouty2 correlates with favorable prognosis of gastric adenocarcinoma via suppressing FGFR2-induced ERK phosphorylation and cancer progression. Oncotarget 2017;8:4888-4900.

24 Zhou Q Chen J, Feng J, Xu Y, Zheng W, Wang J: SOSTDC1 inhibits follicular thyroid cancer cell proliferation, migration, and EMT via suppressing PI3K/Akt and MAPK/Erk signaling pathways. Mol Cell Biochem 2017;10.1007/s11010-017-3059-0

25 Chen B, Zeng X, He Y, Wang X, Liang Z, Liu J, Zhang P, Zhu H, Xu N, Liang S: STC2 promotes the epithelialmesenchymal transition of colorectal cancer cells through AKT-ERK signaling pathways. Oncotarget 2016;7:71400-71416.

26 Lee YM, Kaduwal S, Lee KH, Park JC, Jeong WJ, Choi KY: Sur8 mediates tumorigenesis and metastasis in colorectal cancer. Exp Mol Med 2016;48:e249.

-27 Patel R, Gao M, Ahmad I, Fleming J, Singh LB, Rai TS, McKie AB, Seywright M, Barnetson RJ, Edwards J, Sansom OJ, Leung HY: Sprouty2, PTEN, and PP2A interact to regulate prostate cancer progression. J Clin Invest 2013;123:1157-1175.

28 Abekhoukh S, Planque C, Ripoll C, Urbaniak P, Paul JL, Delabar JM, Janel N: Dyrk1A, a serine/threonine kinase, is involved in ERK and Akt activation in the brain of hyperhomocysteinemic mice. Mol Neurobiol 2013;47:105-116.

29 Chitra E, Lin YW, Davamani F, Hsiao KN, Sia C, Hsieh SY, Wei OL, Chen JH, Chow YH: Functional interaction between Env oncogene from Jaagsiekte sheep retrovirus and tumor suppressor Sprouty2 Retrovirology 2010;7:62.

-30 Lankenau MA, Patel R, Liyanarachchi S, Maharry SE, Hoag KW, Duggan M, Walker CJ, Markowitz J, Carson WE, 3rd, Eisfeld AK, de la Chapelle A: MicroRNA-3151 inactivates TP53 in BRAF-mutated human malignancies. Proc Natl Acad Sci U S A 2015;112:E6744-6751.

-31 Cui R, Meng W, Sun HL, Kim T, Ye Z, Fassan M, Jeon YJ, Li B, Vicentini C, Peng Y, Lee TJ, Luo Z, Liu L, Xu D, Tili E, Jin V, Middleton J, Chakravarti A, Lautenschlaeger T, Croce CM: MicroRNA-224 promotes tumor progression in nonsmall cell lung cancer. Proc Natl Acad Sci U S A 2015;112:E4288-4297.

\$2 Li Q, Li Z, Wei S, Wang W, Chen Z, Zhang L, Chen L, Li B, Sun G, Xu J, Li Q, Wang L, Xu Z, Xia Y, Zhang D, Xu H, Xu Z: Overexpression of miR-584-5p inhibits proliferation and induces apoptosis by targeting WW domaincontaining E3 ubiquitin protein ligase 1 in gastric cancer. J Exp Clin Cancer Res 2017;36:59. 


\section{Cellular Physiology Cell Physiol Biochem 2018;47:1465-1481 \begin{tabular}{l|l} 
and Biochemistry Published online: June 25, 2018 & $\begin{array}{l}\text { C } 2018 \text { The Author(s). Published by S. Karger AG, Base } \\
\text { www.karger.com/cpb }\end{array}$ \\
\hline
\end{tabular} \\ He et al.: MiR-592 Promotes PI3K/AKT and MAPK/ERK Signaling by Inhibiting Spry2 in GC}

-33 Cabrita MA, Christofori G: Sprouty proteins, masterminds of receptor tyrosine kinase signaling. Angiogenesis 2008;11:53-62.

-34 Wu K, Ye C, Lin L, Chu Y, Ji M, Dai W, Zeng X, Lin Y: Inhibiting miR-21 attenuates experimental hepatic fibrosis by suppressing both the ERK1 pathway in HSC and hepatocyte EMT. Clin Sci (Lond) 2016;130:1469-1480.

-35 Barbachano A, Fernandez-Barral A, Pereira F, Segura MF, Ordonez-Moran P, Carrillo-de Santa Pau E, Gonzalez-Sancho JM, Hanniford D, Martinez N, Costales-Carrera A, Real FX, Palmer HG, Rojas JM, Hernando E, Munoz A: SPROUTY-2 represses the epithelial phenotype of colon carcinoma cells via upregulation of ZEB1 mediated by ETS1 and miR-200/miR-150. Oncogene 2016;35:2991-3003.

- 36 Shukla A, Rai K, Shukla V, Chaturvedi NK, Bociek RG, Pirruccello SJ, Band H, Lu R, Joshi SS: Sprouty 2: a novel attenuator of B-cell receptor and MAPK-Erk signaling in CLL. Blood 2016;127:2310-2321.

-37 He S, Zhang J, Lin J, Zhang C, Sun S: Expression and function of microRNA-27b in hepatocellular carcinoma. Mol Med Rep 2016;13:2801-2808.

-38 Sulaiman SA, Ab Mutalib NS, Jamal R: miR-200c Regulation of Metastases in Ovarian Cancer: Potential Role in Epithelial and Mesenchymal Transition. Front Pharmacol 2016;7:271.

39 Satoh K, Hamada S, Shimosegawa T: Involvement of epithelial to mesenchymal transition in the development of pancreatic ductal adenocarcinoma. J Gastroenterol 2015;50:140-146.

40 Zhang JP, Zeng C, Xu L, Gong J, Fang JH, Zhuang SM: MicroRNA-148a suppresses the epithelial-mesenchymal transition and metastasis of hepatoma cells by targeting Met/Snail signaling. Oncogene 2014;33:40694076.

41 Chen SY, Teng SC, Cheng TH, Wu KJ: miR-1236 regulates hypoxia-induced epithelial-mesenchymal transition and cell migration/invasion through repressing SENP1 and HDAC3. Cancer Lett 2016;378:59-67.

42 Gao J, Tian J, Lv Y, Shi F, Kong F, Shi H, Zhao L: Leptin induces functional activation of cyclooxygenase-2 through JAK2/STAT3, MAPK/ERK, and PI3K/AKT pathways in human endometrial cancer cells. Cancer Sci 2009;100:389-395.

43 Feng Y, Xu X, Zhang Y, Ding J, Wang Y, Zhang X, Wu Z, Kang L, Liang Y, Zhou L, Song S, Zhao K, Ye Q: HPIP is upregulated in colorectal cancer and regulates colorectal cancer cell proliferation, apoptosis and invasion. Sci Rep 2015;5:9429.

44 Chiu D, Ma K, Scott A, Duronio V: Acute activation of Erk1/Erk2 and protein kinase B/akt proceed by independent pathways in multiple cell types. FEBS J 2005;272:4372-4384.

45 Grille SJ, Bellacosa A, Upson J, Klein-Szanto AJ, van Roy F, Lee-Kwon W, Donowitz M, Tsichlis PN, Larue L: The protein kinase Akt induces epithelial mesenchymal transition and promotes enhanced motility and invasiveness of squamous cell carcinoma lines. Cancer Res 2003;63:2172-2178.

46 Hori S, Wadhwa K, Pisupati V, Zecchini V, Ramos-Montoya A, Warren AY, Neal DE, Gnanapragasam VJ: Loss of hSef promotes metastasis through upregulation of EMT in prostate cancer. Int J Cancer 2017;140:18811887.

47 Gao M, Patel R, Ahmad I, Fleming J, Edwards J, McCracken S, Sahadevan K, Seywright M, Norman J, Sansom 0, Leung HY: SPRY2 loss enhances ErbB trafficking and PI3K/AKT signalling to drive human and mouse prostate carcinogenesis. EMBO Mol Med 2012;4:776-790.

48 Mason JM, Morrison DJ, Basson MA, Licht JD: Sprouty proteins: multifaceted negative-feedback regulators of receptor tyrosine kinase signaling. Trends Cell Biol 2006;16:45-54.

-49 Ichiyama K, Gonzalez-Martin A, Kim BS, Jin HY, Jin W, Xu W, Sabouri-Ghomi M, Xu S, Zheng P, Xiao C, Dong C: The MicroRNA-183-96-182 Cluster Promotes T Helper 17 Cell Pathogenicity by Negatively Regulating Transcription Factor Foxo1 Expression. Immunity 2016;44:1284-1298.

50 Samuel N, Wilson G, Lemire M, Id Said B, Lou Y, Li W, Merino D, Novokmet A, Tran J, Nichols KE, Finlay JL, Choufani S, Remke M, Ramaswamy V, Cavalli FM, Elser C, Meister L, Taylor MD, Tabori U, Irwin M, Weksberg R, Wasserman JD, Paterson AD, Hansford JR, Achatz MI, Hudson TJ, Malkin D: Genome-Wide DNA Methylation Analysis Reveals Epigenetic Dysregulation of MicroRNA-34A in TP53-Associated Cancer Susceptibility. J Clin Oncol 2016;10.1200/JC0.2016.67.6940

-51 Wang L, Feng D, Liu Y, Li S, Jiang L, Long Z, Wu Y: Autophagy plays a protective role in motor neuron degeneration following spinal cord ischemia/reperfusion-induced spastic paralysis. Am J Transl Res 2017;9:4261-4270.

52 Rupaimoole R, Slack FJ: MicroRNA therapeutics: towards a new era for the management of cancer and other diseases. Nat Rev Drug Discov 2017;16:203-222. 